\title{
Levante artístico - diverso e disperso
}

\author{
Artistic Uprising - diverse and diffuse
}

Gustavo Falabella Rocha ${ }^{1}$ 


\section{Resumo}

O artigo analisa o trabalho da Zona de Arte da Periferia - ZAP 18, de Belo Horizonte em sua sede, no bairro Serrano. Com pesquisa voltada para teatro e realidade(s), a ZAP 18 leva à cena questões de interesse coletivo, como a criminalidade, a história do Brasil, o transporte público, as relações humanas e capitalistas, a paixão pelo futebol, entre outras. Para mais, com as dificuldades para manutenção de seu espaço e de seus integrantes, o grupo encontrou uma forma criativa de se manter ativo, por meio da construção do "levante artístico", conceito edificado em torno de relações artísticas temporárias, que se dão mais em virtude do espaço do que pela relação enraizada de seus integrantes.

Palavras-chave: Levante artístico; ZAP 18; teatro político; teatro; realidade
This article portrays the artistic work of Zona de Arte da Periferia - ZAP 18, of Belo Horizonte, in its headquarters at Serrano. With a research based upon theater and realities, ZAP 18 has addressed matters of collective interest, such as the criminal events in Brazilian cities, History of Brazil, means of transportation, human and capitalist relations, the football passion, among others. Furthermore, considering all the difficulties of maintaining the company's headquarters and company members, ZAP 18 found a creative way of keeping itself active, through a new relationship - that I will address here as "artistic uprising" - based on temporary artistic bonds, around mostly the company's headquarters.

Keywords: Artistic uprising; ZAP 18; political-theater; theater; reality 


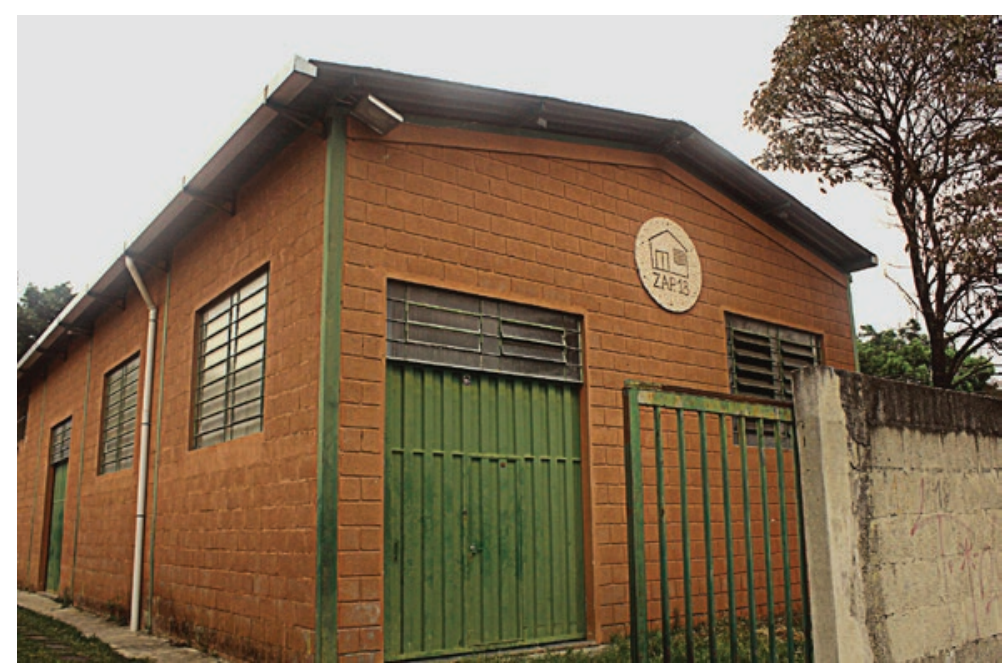

Imagem 01 - Sede da ZAP 18 - vista de fora. Arquivo pessoal

Novas soluções para novos tempos, com essa premissa a Zona de Arte da Periferia (ZAP 18) adaptou seu trabalho artístico ao contexto econômico de precarização de editais de financiamento à cultura buscando uma solução para manter-se ativa mesmo em tempos adversos. Em 2002, o grupo inaugurou sua sede no bairro Serrano, na periferia de Belo Horizonte e, desde então, desenvolve um trabalho com forte carga crítica e política abordando temáticas de interesse coletivo, como a criminalidade nas grandes cidades, a história do Brasil, o caos urbano, etc. O trabalho realizado pela companhia está alinhado diretamente a um sentimento de pertencimento ao lugar que ocupa, o bairro Serrano, embora não se restrinja a essa geografia ao estabelecer experiências espaciais por outros espaços em Belo Horizonte e seu entorno.

A ZAP 18 é um coletivo artístico que possui sua sede - de mesmo nome, no bairro Serrano, regional Pampulha de Belo Horizonte - há 17 anos e lá desenvolve sua pesquisa voltada para teatro e realidade(s). Na trajetória do grupo, destacam-se trabalhos como Esta Noite Mãe Coragem (2006), 1961-2009 (2009) e Homem Vazio na Selva da Cidade (2017), espetáculos que trazem um forte posicionamento do grupo diante de fatos, situações e contextos sociais prementes que fazem parte da rotina de seus integrantes e de seus vizinhos no bairro Serrano e região. Esta Noite Mãe Coragem se espelha em Mãe Coragem e seus filhos, de Bertolt Brecht, para falar da criminalidade e das contradições de uma mãe - moradora da periferia de uma grande cidade brasileira - que se mantém por meio de práticas ilegais que contribuem para ceifar a vida de sua família; 1961-2009 busca retratar a história do Brasil no período que lhe dá nome, por meio de músicas marcantes e pelo olhar dos jovens e dos movimentos sociais. A peça cumpriu seis anos de carreira e buscava se atualizar com os novos acontecimentos como uma longa linha do tempo. As passeatas de junho de 2013 e as eleições de 2014 foram dois momentos de tensão em que o espetáculo buscava ecoar, problematizar e discutir os muitos gritos e questões vindas das ruas de Belo Horizonte e do Brasil como um todo; e Homem Vazio na Selva da Cidade narra a história de um escritor vazio de ideias que vive no interior e se vê obrigado a ir à cidade grande para negociar o contrato de seu último livro. Uma vez na cidade, ele é exposto às contradições e desequilíbrios da metrópole: crime, exclusão, desva- 
lorização da vida humana e jogos de poder são alguns dos assuntos que vêm à tona na obra.

É importante destacar que os três trabalhos citados representam o aprofundamento de algumas práticas artísticas, que são parte da rotina do grupo em seus ensaios. Entre elas: 1. o desejo de processos horizontais, por meio de exercícios criativos de preparação para a cena; 2. o caderno de protocolo, instrumento de registro coletivo dos ensaios, inspirado nas práticas do teatro didático de Bertolt Brecht, que depois foram estudadas pela professora e pesquisadora Ingrid D. Koudela e 3. a elaboração de narrativas em primeira pessoa para trazer os depoimentos e subjetividades para as peças do grupo².

Hoje, em 2019, a ZAP 18 se divide em diversas frentes de trabalho artístico. Há uma rotina de coletivo artístico, mas o que tem marcado os últimos cinco ou seis anos do espaço tem sido sua utilização múltipla. Diversa e dispersa. Diversa pela multiplicidade de artistas que se engajam em projetos gestados, ensaiados e/ou produzidos na ZAP 18; dispersa, pois tais ações artísticas não são necessariamente convergentes, muitas vezes, o que as une é o simples fato que elas ocorrem num mesmo espaço.

Há alguns anos, a ZAP 18 tem assumido, mais e mais, a natureza de zona presente em seu DNA. Isso é, o grupo, a ZAP 18, tem se transformado em um espaço de convergência de ideias, projetos e inquietações artísticas. Tornando-se, mais e mais, uma zona do que propriamente um grupo fixo de artistas que desenvolve seus trabalhos, como acontece tradicionalmente nos grupos de teatro. Não se trata, obviamente, de uma crítica ou de uma comparação que diminua a importância da prática de vários grupos ao longo da história do teatro. Trata-se, na verdade, de uma constatação de como a ZAP 18, especificamente, tem se transformado em sua prática nos últimos anos. É importante deixar claro que tal configuração-constituição diz respeito a um interregno, uma transição, um meio do caminho. A concepção do grupo não elimina o desejo de um trabalho continuado, de uma prática enraizada com integrantes que possam se dedicar à rotina artística do grupo. Assim, o espaço, a zona, é um espaço de convergência, de encontro.

Outro aspecto que se reverbera na formação do grupo são as relações com menos enraizamentos se deram (dão) também por conta de uma precariedade econômica para manter integrantes engajados e exclusivamente dedicados ao espaço e à criação no grupo. Pesa, positivamente, o fato do grupo ser dono do espaço e não ter despesas com aluguel, o que oneraria sobremaneira a manutenção de seu trabalho.

2 Para saber mais sobre os trabalhos da ZAP 18, seus espetáculos e desdobramentos, sugiro as leituras: Gustavo Rocha. Práticas artísticas horizontais: a experiência da ZAP 18 no bairro Serrano, EBA-UFMG, 2017; Maria A. V. Falabella Rocha. De Sonho \& Drama a ZAP 18: a construção de uma identidade. Dissertação de Mestrado, EBA-UFMG, 2006. Júlia Guimarães Mendes. Teatralidades do Real: significados e práticas na cena contemporânea. Dissertação de Mestrado, EBA-UFMG, 2012 e Julia Guimarães Mendes. As Teatralidade do real no espetáculo Esta Noite Mãe Coragem. Pós: Belo Horizonte, v.3, n.6, p.8 - 22, novembro, 2013. O espetáculo 1961-2009 pode ser visto, na íntegra, no Youtube: https://www.youtube.com/watch?v=pLKOtCik134 


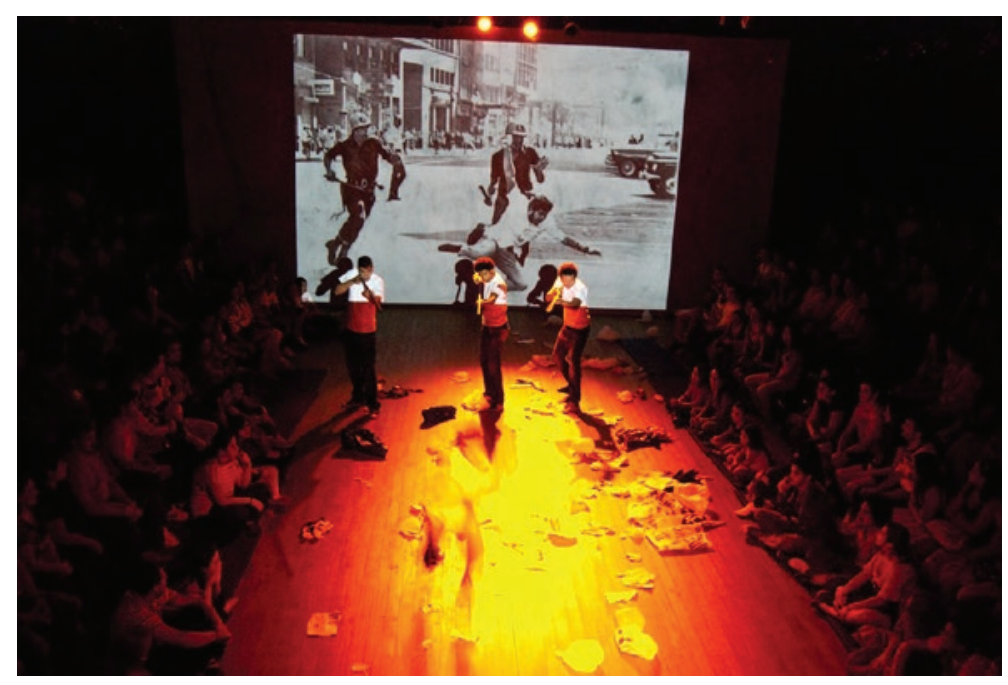

Imagem 2 - Cena do espetáculo 1961-2009. Foto: Thalita Silva. Arquivo ZAP 18

Para ajudar a formulação teórica que aqui faço, ao passo que relato o trabalho da ZAP 18, busco em Hakim Bey, a comparação entre levante e revolução para então propor um novo conceito. Em seu livro TAZ ${ }^{3}$ - Zona Autônoma Temporária (Temporary Autonomous Zone, 2001), Bey explica a diferença entre ambas. Segundo o autor, historicamente, o levante ou a insurreição são vistos como tentativas de revolução não concretizadas, tomadas de poder frustradas. Por sua vez, as revoluções conseguem romper com a ordem e trazem uma nova organização política que será novamente suprimida por um novo sistema de dominação social, que se assemelhará com aquele que tanto criticava, de início. Ou seja, o espírito revolucionário apenas reorganiza os sistemas de exploração de homem sobre homem, muda-se o nome e/ou mecanismo, mas não seu princípio 4 . Segundo Bey (2001, p. 15): "[...] a volta completa, o eterno retorno da história, uma vez e outra mais, até o ápice: botas marchando eternamente sobre o rosto da humanidade".

Para Bey (2001), o levante se transforma em uma opção de ação política atrativa porque ele rompe momentaneamente com a ordem estabelecida, em um tempo e espaço curtos e não deixa rastros, desdobramentos e consequências. O levante é, pois, uma forma de resistência capaz de provocar rupturas temporárias e autônomas. Com caráter performático, ele acontece uma única vez e não se repete. $O$ autor aponta que, comparado ao padrão "normal" de experiência e consciência, um levante seria uma "experiência de pico". "Como os festivais, os levantes não podem acontecer todos os dias ou não seriam 'extraordinários'. Mas tais momentos de intensidade moldam e dão sentido a toda uma vida" (Bey, 2001, p. 16).

\footnotetext{
3 Em seu livro, Bey não define a TAZ como um verbete de dicionário. No entanto, ao longo do texto, ele vai nos dando algumas dicas do que seja. No meu entendimento, ele enxerga a TAZ como uma espécie de ação de contracultura, que se estabelece nas brechas, buscando levantes e não revoluções. $O$ autor foge das grandes utopias e ideologias, pois crê que elas levaram a humanidade a um estado não muito bom. Nas palavras dele: "A TAZ é um acampamento de guerrilheiros ontologistas: ataque e fuja. Continue movendo a tribo inteira, mesmo que ela seja apenas dados na web. A TAZ deve ser capaz de defender; mas, se possível, tanto o 'ataque' quanto a 'defesa' devem evadir a violência do Estado, que já não é uma violência com sentido. $O$ ataque é feito às estruturas de controle, essencialmente às ideias" (Bey, 2001, p. 19). N.A.

4 Vale lembrar que o livro de Bey é da década de 1980 e parece ser influenciado por um grande desgaste das macronarrativas, os "ismos" capazes de dar solução definitiva plena para a vida das pessoas, como um todo. Seu pessimismo se assemelha às narrativas futurísticas e catastróficas de alguns autores, como George Orwell e Aldous Huxley, respectivamente em seus livros "1984" e "Admirável Mundo Novo". N.A.
} 
Não foi por acaso que comecei esse item falando sobre a tendência de zona presente na organização e trabalhos da ZAP 18. Entendo que esse espaço de convergência de ideias e proposições artísticas estreita suas relações com a ideia de levante proposta por Bey ${ }^{5}$, sobretudo a partir do espetáculo 1961-2009, como essa relação fluída que as pessoas desenvolvem entre si e o espaço. Isso é, a partir desse trabalho, as relações profissionais dentro da ZAP 18 ganharam flexibilidade, até como retrato de uma realidade na qual as pessoas desenvolvem e se envolvem com várias coisas ao mesmo tempo. Contudo, é importante ressaltar uma diferença fundamental, pois o teatro, sim, deixa seus rastros, desde as impressões mais pessoais causadas por uma apresentação até desdobramentos de um trabalho, muito tempo depois, que não se imaginaria lá atrás ${ }^{6}$. Também, há uma trajetória do grupo ZAP 18 e do espaço que convergem, dialogam, de modo que o levante corrobore também com essa prática artística do grupo e de sua sede, na construção de linguagem e identidade de seu trabalho ao longo do tempo.

De tal forma, de modo a diferenciar o levante proposto por Bey (2001) das práticas espaciais e artísticas ocorridas na ZAP 18, proponho que se possa pensar em um levante artístico, que se refere às criações artísticas ocorridas em determinado tempo e espaço, proporcionando "experiências de pico" - ou seja que fujam à rotina e sejam marcados por seu caráter extraordinário -, deixando (ou não) rastros, sejam eles no espaço, no imaginário pessoal ou coletivo de quem as viu. Outro ponto importante, que não fica evidente na obra de Bey é a preparação para tais experiências de pico ou levantes. No seu livro, ele não faz menção a esse momento que antecede as rupturas, talvez, porque ele não considere relevante ou simplesmente porque esse momento é inexistente. No caso de um levante artístico, como discuto aqui, a preparação, ainda que rápida, se faz presente e é fundamental para formular as bases do trabalho.

O levante artístico pode ser visto também como performance. Por outro lado, se pensarmos, junto com Bey, que o levante artístico também é algo que não se repete e que promove rupturas temporárias dentro do próprio sistema, poderemos entender que ele se trata, na realidade, da própria prática artística da ZAP 18. Explico: o grupo e sua sede poderiam ser vistos como uma ponte. Isso é, estaríamos/ocuparíamos mais de um lugar concomitantemente. Vale destacar que, mesmo com sua sede localizada na periferia de Belo Horizonte, a ZAP 18 ocupa um lugar importante na cena teatral da cidade participando de eventos de destaque, como o Festival Internacional de Teatro de Belo Horizonte (FIT - BH Palco \& Rua), Encontro Mundial de Artes Cênicas (Ecum), entre outros festivais e ciclos de discussão. Ou seja, geograficamente, podemos considerar a ZAP 18 periférica, mas no mapa da produção teatral da cidade, o grupo tem sua centralidade.

\footnotetext{
5 Também é possível discutir as ações políticas, de levante, que não se relacionem com nenhuma outra ideologia e que não deixam rastros para o futuro - como afirma Bey. Se pensarmos, numa construção histórica, de sedimentação de vários movimentos e inquietações, veremos que é difícil conceber algo que "nasça" do nada, como ideia original. Mesmo as ações reprimidas e esporádicas se relacionam com outras e com o histórico [de lutas] daquele lugar. Mas como essa discussão não é o foco deste arquivo, vou "concordar" com Bey e seguir adiante. N.A.

6 Embora pareça óbvio não é demais ressaltar que ambos têm zona em sua gênese: Zona Autônoma Temporária, a TAZ de Bey e Zona de Arte da Periferia ZAP 18.
} 
Ocupar mais de um lugar nos permite trânsitos pela cidade e uma prática espacial constante, como os Rolezinhos da ZAP $18^{7}$ e as muitas ocasiões em que saímos de nosso espaço para promover outras ações ou mesmo quando recebemos outros artistas em nossa sede para que eles desenvolvam ou apresentem seus trabalhos ${ }^{8}$. Assim, de dentro do "sistema", a ZAP 18 vai construindo sua trajetória de um teatro imbuído de assuntos relevantes de diversas realidades, teatro que pensa em rupturas, que levanta questionamentos e que não se conforma em pensar que o mundo é imutável enraizado em uma narrativa única hegemônica. Nesse sentido, sua prática criativa horizontal - que se aprofunda com a construção do espetáculo 1961-2009 - se revela como uma grande força de resistência e ruptura com o status quo capitalista, porque ela se opõe ao caminho vertical visto, praticado e disseminado em quase todos os lugares da sociedade capitalista.

Entendo também que o levante de Bey (2001) pode ser uma resposta às múltiplas narrativas vividas nos dias atuais. Quero dizer que, diferentemente de outros tempos em que se projetava um horizonte de revoluções, hoje percebo que - mesmo no seio de alguns movimentos sociais e políticos - existem bandeiras mais urgentes e pontuais, como o combate à LGBTfobia $^{9}$, ao machismo, ao preconceito racial e inúmeros outros preconceitos; há a questão da mobilidade urbana, do transporte público, da descriminalização das drogas e tantas outras. E coincidentemente [ou não], as questões levantadas pelos atuais integrantes da ZAP 18 apontam para a discussão de pautas, como essas, porque as pessoas com que temos trabalhando ultimamente são frutos desse meio caótico e polimorfo que é a cidade grande contemporânea. Suas subjetividades e poéticas dialogam com o meio onde elas vivem. É o caso, por exemplo, das pautas femininas e feministas que vieram à tona com uma nova geração de atrizes, que trabalham na ZAP 18, como Sheyla Sant'Ana, Micheline Monteiro Dominique Machado Bezerra e Raiane Oliveira. As opressões sofridas pelas mulheres e a força de suas lutas se tornaram parte importante no espetáculo Homem Vazio na Selva da Cidades. Há também a questão racial que se mostra muito presente em Memórias Póstumas de um Neguinho, espetáculo solo de Lucas Costa, que revela os conflitos, preconceitos e dificuldades vividas por ele em sua infância, juventude e primeiros anos da vida adulta.

\footnotetext{
7 Inspirados pelo Rolezinhos ocorridos nas grandes cidades brasileiras, principalmente São Paulo e Rio de Janeiro, em 2014, pensamos em criar os Rolezinhos da ZAP 18, que seriam as incursões do grupo em espaços tidos como nobres na cidade. Assim, fizemos temporadas do espetáculo "O Gol não valeu!", no Centro Cultural Banco do Brasil e o Teatro Francisco Nunes, ambos em Belo Horizonte.

8 A Cia. Candongas, Os Conectores, Grupo Trama, Os Arturos, Cóccix, Grupo Quatroloscinco, Teatro Invertido, Teatro 171, Grupo Oriundo, Zula, Mostra BH in Solos, Cia. Crônica, Mostra Teatro e Direitos Humanos (MOTEH), Trupe Pierrot Lunar, Luna Lunera, Maria Cutia, Cia. Lúdica, Cia. Acômica, Pigmaleão Escultura que Mexe são alguns dos grupos que se apresentaram e/ou ofereceram oficinas ou aulas abertas na ZAP 18, ao longo dos 17 anos do espaço.

9 Embora as siglas LGBT, LGBTT e LGBTTQ+ e outras variações sejam utilizadas como sinônimos, cada uma delas agrega uma letra representante de uma orientação sexual e/ou identidade de gênero como forma de abarcar toda a diversidade que compõe essa minoria. Para esta pesquisa, no entanto, será utilizado a sigla LGBT como forma de aproximação ao objeto empírico, cujo nome é LGBT Brasil. Com isso, o trabalho não menospreza todas manifestações para além da sigla, pelo contrário: entendemos que as siglas, mesmo distintas, compartilham o objetivo comum de abarcar a minoria social referida em toda sua complexidade. Ademais, acreditamos que nenhuma sigla é capaz de integrar completamente as variações e nuances relacionadas aos espectros da sexualidade e da identidade de gênero.
} 
O artista ao olhar para a cidade e projetar seu trabalho em diálogo com essa pluralidade que uma grande metrópole ${ }^{10}$ abriga, conviverá com duas forças antagônicas. Se, por um lado, ele critica o ritmo frenético, o alheamento, as relações superficiais, a atitude blasé e tantas outras consequências da vida em uma grande cidade, é justamente esse cenário que lhe dará os elementos para criação de seu trabalho. Ou seja, embora critique, o artista urbano não existe sem a urbanidade e seus distúrbios. Paola Berestein Jacques (2012), em Elogio aos Errantes, nos conta que tal dilema é sentido desde os tempos do flâneur, de Charles Baudelaire, na Paris, do século XIX, passando pelos dadaístas, do início do século XX e também pelos situacionistas de meados do século passado. Arrisco-me a dizer que as metrópoles seguem movendo paixões e ódios, no devir artístico de muitos. No caso da ZAP 18, as cidades grandes são nosso cenário mais rico, mais polimórfico e complexo - onde os conflitos do capitalismo e das relações em sociedade estão mais evidentes (e caóticos).

A transitoriedade presente na prática artística da ZAP 18 e seus espetáculos não teve desdobramentos e consequências apenas para os momentos em que a ZAP 18 saiu de sua casa para fazer trabalhos em outros lugares. $O$ trânsito também se fez (faz) presente como uma resposta aos tempos que vivemos hoje, como uma nova possibilidade de organização em meio ao caos e às relações fluidas da atualidade, bem como à dificuldade abissal em se manter economicamente um grupo de teatro e seus integrantes. A ZAP 18 se reinventou valendo-se justamente da ideia de espacialidades transitórias. Isso é, como algo que se forma temporariamente, proporciona experiências criativas, artísticas e/ou de apreciação e logo se desfaz, deixando alguns rastros. Adiante, uma nova experiência, que se aproveita dos vestígios deixados pela anterior. Ou não necessariamente. Em comum, o espaço físico, as paredes de seu galpão abrigando essas experiências de pico. A essas experiências presentes nesse novo momento do grupo, propus - em diálogo com Hakim Bey - o nome de levante artístico. Com isso, desejo apontar para uma experiência de pico provisória, uma convergência de artistas que habitam a ZAP 18 [ou outra espacialidade] por determinado tempo e espaço e, juntos, promovem ações artísticas.

De tal maneira, o que pretendo ressaltar é que a ZAP 18 segue proporcionando experiências espaciais, como um lugar de poéticas políticas próprias. Assim sendo, é possível pensar que tal lugar é praticado na rotina criativa. E muito embora, o lugar (físico) abrigue essas iniciativas artísticas, ele não as aprisiona. Isso é, a prática errática de espacialidades provisórias e/ou temporárias segue valendo, assim como também segue pertinente pensar com Jacques (2012) sobre construções de alteridade pela prática do espaço.

Um lugar de poéticas políticas próprias seria capaz de abrigar as ambivalências, entre o global e o local, entre público e privado. Seria um lugar onde as narrativas pessoais estariam enredadas com aspectos mais abrangentes, com bandeiras de lutas atuais - como as que descrevo quando falo sobre as questões prementes dos atuais

10 Pensando também a cidade, seus habitantes e seus movimentos, o pesquisador Henri Lefebvre (2001, p. 135) nos atenta que "o futuro da arte não é artístico, mas urbano". Creio que ele já imaginava que uma arte engajada com as questões do seu tempo e de seu espaço, projetando seus embates no cenário mais emblemático do capitalismo: as cidades grandes. Lefebvre é fundamental na discussão e pensamento dos fluxos das cidades. Ele não foi abordado neste artigo, pois optei por seguir outros caminhos que não necessariamente, na minha opinião, dialogavam com sua rica obra. 
integrantes da ZAP 18. Por poéticas políticas próprias, entendo a construção de uma subjetividade calcada na consciência do sujeito como ser social, como sujeito histórico, participante de contextos coletivos complexos, em relação com outros sujeitos. O artista que lança seu olhar para tais contextos pode ser capaz de desenvolver um olhar crítico na construção de suas poéticas, sem deixar de lado, no entanto, seus desejos e suas histórias pessoais mais íntimas.

\section{O espaço como catalisador de experiências criativas}

A experiência dos últimos anos do coletivo, tem se transformado, paulatinamente, nessas experiências de enlevamento provisório. Se antes, a estrutura do grupo se definia por integrantes reconhecíveis e aplicados na manutenção do espaço e também na criação, na sala de ensaio, hoje o espaço é um catalisador de encontros de vários artistas. Embora haja, sim, pessoas que sejam referências do espaço ou da criação artística, a ZAP 18 tem se organizado mais e mais com a lógica do levante: uma "experiência de pico" vivida por um número de pessoas - seja em uma oficina, em uma intervenção ou mesmo em um espetáculo - que depois poderá (ou não) se refazer mais adiante, com outras pessoas, em outros termos. É importante ressaltar, para além de idealismos, que as experiências criativas mais recentes da ZAP 18 se enquadram como algo que se dá em um tempo e espaço determinado e com chances reais de não serem realizadas novamente. Seu "extraordinário" se dá nessa possibilidade de fugir da rotina em um curto tempo-espaço e também por seu caráter fugaz ${ }^{11}$.

É o caso de $O$ que você tem a ver com isso? - um apanhado de cenas de alguns espetáculos do histórico do grupo, que foi apresentado no Sesc Palladium, em julho de 2016. Sem contar com vários dos integrantes dos elencos originais, o grupo lançou mão daqueles mais próximos que frequentavam as oficinas para compor um espetáculo/intervenção que começava nas ruas próximas e entrava pelo teatro. Foram apresentadas cenas de Esta Noite Mãe Coragem, 1961-2009 e de um novo trabalho, que ainda não estava em processo de ensaio e que tinha apenas uma primeira versão de seu texto escrito por Francisco Rocha: Homem Vazio na Selva da Cidade. A potência da experiência se encerrou ali. A intervenção não foi repetida e Homem Vazio na Selva da Cidade estreou, com outro formato, na própria ZAP 18, em novembro de 2017.

Há também o caso da intervenção ZAP Conta João, quando o grupo foi convidado pelo Festival de Inverno da UFMG, em 2015, para fazer uma homenagem aos 80 anos do encenador, ator e dramaturgo João das Neves. Na ocasião, Cida Falabella escolheu três montagens de diferentes momentos da carreira de João buscando trazer à cena a complexidade de sua obra e trajetória. Assim, o grupo formado, mais uma vez, por atores do grupo profissional da ZAP 18 e também por alunos de oficinas, ensaiaram uma cena de $O$ último carro, espetáculo montado no Rio de Janeiro,

\footnotetext{
11 É preciso considerar que existem produções - sobretudo de teatro - que reúnem artistas para um trabalho de poucos meses de ensaio, que virá a ser um espetáculo. Esse tipo de experiência não é o caso da ZAP 18, já que - como argumentei anteriormente - os rastros dos trabalhos anteriores e das relações entre os artistas permanecem e se desdobram (fato que também pode ocorrer nesse tipo de "ajuntamento"). Portanto, preferi não abordar essas produções aqui, porque não há tantos pontos de contato com a trajetória da ZAP 18.
} 
na década de 1960, aclamado pela crítica e vencedor de importantes prêmios como - Moliére de teatro; Soroco, sua mãe e sua filha, adaptação do conto homônimo de Guimarães Rosa, montado como um espetáculo itinerante no Parque Lagoa do Nado, em Belo Horizonte e um cântico indígena, escolhido para representar os anos vividos no Acre, quando João viveu em uma tribo com os Kashinawa. A intervenção se apresentou uma vez na abertura do festival de inverno e somente outra vez em uma mostra de espetáculos de João das Neves, promovida pelo Sesc Palladium, em Belo Horizonte.

Além dessas, desde os últimos meses de 2016, há um coletivo batizado de ZAP Ampliada, formado por pessoas que se relacionam de várias maneiras com o espaço. Uma das responsabilidades do grupo é viabilizar as atividades do galpão e garantir sua manutenção, desde sua limpeza, passando por sua organização física e pagamento de suas despesas básicas. Sem organograma ou banco de horas, a ideia é uma relação difusa com o espaço: cada um contribui dentro de suas possibilidades.

É importante destacar o sentido de horizontalidade dessas construções, entre artistas de diferentes experiências e idades. A diversidade de vozes e experiências de vida e artística é, aliás, algo presente nos trabalhos da ZAP 18 desde sua abertura. Esse encontro geracional marca o dia a dia do espaço. Cada um contribuiu com suas vivências e com sua bagagem. Dessa maneira, o trabalho da ZAP 18 dialoga com a cidade, agregando pessoas que vivem em diferentes regiões de Belo Horizonte e região metropolitana, com suas respectivas realidades sociais. Isso, seguramente, não quer dizer que o grupo não busque fazer o melhor trabalho artístico ao seu alcance em prol de um discurso ou posição política, mas sim reconhecer e respeitar a diferença entre pessoas com vidas e trajetórias diferentes. $O$ teatro como palco/retrato da realidade que o rodeia. Assim, na ZAP 18, o trabalho artístico sempre foi "da porta para fora", em um diálogo constante entre o que vem da rua e como isso nos afeta em nossa rotina de artistas.

\section{Conclusão}

A ideia do levante artístico é uma possibilidade de organização encontrada pelo grupo. Uma nova forma de relacionamentos artísticos horizontais. Não significa, no entanto, que a ZAP 18 não deseje ainda desenvolver trabalhos continuados, de longo prazo, de pesquisa, com seus artistas e com os alunos de suas oficinas. Tampouco, não quer dizer que o grupo não deseje investir em seu repertório e em outras frentes de trabalho. $O$ coletivo não nega suas origens de grupo de teatro. Contudo, o levante se transformou em uma resposta artística da ZAP 18 para tempos extremos. Tempos de diminuição de verbas, de não reconhecimento da cultura como direito e como setor produtivo e econômico. Em um contexto de Golpe, é preciso pensar em novas formas de organização. São diversos retrocessos, como a crescente onda de recriminação de artistas que são taxados como "pedófilos" ou "pervertidos", com seus trabalhos questionados por uma população pouco acostumada com expressões artísticas de qualquer natureza e com o agravante da cegueira e do fanatismo religioso, como ocorreu em exposições em Porto Alegre, Belo Horizonte e São Paulo. O levante artístico, para a ZAP 18, parece ser uma possibilidade viável. 
Considero importante destacar os traços de algumas formas de pensar e conceber o teatro que se fizeram presentes na longa trajetória da ZAP 18. Como artistas formados em meio a uma série de influências, posso afirmar que o trabalho é moldado por várias delas, seguindo a busca de construção de um teatro crítico, politicamente engajado. A ideia de levante artístico, mais uma vez, pode ser vista na nova configuração da $Z A P 18$ demonstrando que é preciso pensar outras maneiras de se fazer política e, consequentemente, também novas formas de se fazer teatro (político) nos tempos que vivemos hoje em Belo Horizonte (no Brasil, no mundo...). Ou seria o contrário: novas formas de fazer teatro e, consequentemente, de se fazer política? Fato é, com o agravamento das condições de trabalho (os jargões marxistas, infelizmente, não saem da moda) dos artistas - com corte de verbas, extinção do Ministério da Cultura e de prêmios, leis de incentivo com orçamentos reduzidos, entre outros - a possibilidade de manutenção econômica de um grupo fixo de artistas ou de um espaço diminuiu exponencialmente. Com isso, o caminho encontrado pela ZAP 18 foi investir na ideia de um lugar potente, que abrigue iniciativas artísticas efêmeras, que "desapareçam no ar". Assim como um levante. As experiências de pico, como nos fala Hakim Bey, surgem, cumprem sua função artístico-política e desaparecem.

\section{Referências}

BEY, Hakim. TAZ: Zona Autônoma Temporária. São Paulo: Conrad Editora Coleção Baderna, 2001.

JACQUES, Paola Berestein. Elogio aos Errantes. Salvador: EDUFBA, 2012.

MENDES, Júlia Guimarães. Teatralidades do Real: significados e práticas na cena contemporânea. Dissertação de Mestrado, EBA-UFMG, 2012

MENDES, Júlia Guimarães. As Teatralidade do real no espetáculo Esta Noite Mãe Coragem. In: Pós: Belo Horizonte, v.3, n.6, p.8 - 22, novembro, 2013.

ROCHA, Gustavo Falabella. Práticas artísticas horizontais: a experiência da ZAP 18 no bairro Serrano. Dissertação de Mestrado, EBA-UFMG, 2017.

ROCHA, Maria Aparecida Vilhena Falabella. De Sonho \& Drama a ZAP 18: a construção de uma identidade. Dissertação de Mestrado, EBA-UFMG, 2006.

Recebido em: 30/07/2019

Aprovado em: 11/10/2019 